\title{
Um experimento de fabricação digital: parametrização, prototipagem e fabricação de painel
}

Jorge Alexandre Salvador de Alcântara Filho

Graduando em Arquitetura e Urbanismo, UFPE

jorge.alcantarafilho@gmail.com

\section{Leticia Teixeira Mendes}

Doutorado em em Arquitetura, Tecnologia e Cidade Departamento de Expressão Gráfica, UFPE

leticiamendes.edu@gmail.com

\section{RESUMO:}

As técnicas de fabricação digital e prototipagem rápida já são tecnologias consistentes e cada vez mais presentes nos campos de design e construção. A presença cada vez mais significativa dos sistemas de representação e fabricação com auxílio de computador (Computer Aided Design e Computer Aided Manufacturing) na concepção dos mais variados artefatos, tem sido um assunto muito discutido nos diversos campos da indústria criativa. Paralelamente à esta discussão, a introdução da abordagem projetual paramétrica tem uma grande importância na obtenção de novas perspectivas e inovação no design. Dessa forma, com o intuito de associar o potencial das ferramentas de prototipagem rápida e fabricação digital e de um sistema generativo de projeto, este artigo descreve o desenvolvimento de um projeto de mobiliário - um painel para exposição de objetos e organizador de ferramentas - através da documentação detalhada dos processos e procedimentos realizados para sua conclusão e desdobramentos acerca da mudança de paradigma no processo de projeto, condizente com a potencialidade dos recursos digitais. 0 texto do resumo deve ser escrito em Cambria tamanho 10, justificado, espaçamento simples, antes 0 , depois 0. Deve possuir no máximo 200 palavras. 0 texto deve ser escrito em um único parágrafo e conter as informações principais do artigo como objetivos, resultados, métodos, etc.

Palavras-chave: parametrização; prototipagem; fabricação digital; design paramétrico. 


\section{INTRODUÇÃO}

A representação geométrica através de arquivos digitais já é um procedimento usual no processo de design. CAD/CAM (Computer Aided Drawing, Computer Aided Manufacturing) tem sido a principal técnica de design e engenharia industrial por mais de 50 anos (IWAMOTO, 2013). 0 CAD foi, em essência, um translado das técnicas tradicionais de desenho para o meio digital, que permitiu maior precisão e controle das composições, através do controle em camadas e de propriedades referentes a cada 'traço'. Em meio digital, o registro preciso das formas tornou possível a fabricação exata de objetos, partes da construção (como por exemplo: fôrmas de concreto) até mesmo o edifício como um todo, a partir do uso das máquinas automatizadas (Computer Numerically Controlled, ou CNC).

Em contraposição ao paradigma da repetição imposto pela produção em massa, o uso de tecnologias de prototipagem rápida (PR) e fabricação digital (FD) permitiram produzir de maneira muito mais rápida e discutir o conceito de personalização em massa1. A partir de uma abordagem projetual paramétrica, torna-se possível o desenvolvimento do desenho preciso dos elementos que compõe cada peça, assim como a alteração facilitada das características desses elementos. Dentro desse paradigma de concepção e representação, a presente experiência possibilitou destacarmos dois problemas: as limitações de edição impostas pelo software utilizado no processo de design, e a necessidade de tais alterações serem continuamente submetidas às convenções e consistências do designer.

No sentido de reduzir e agilizar essas tarefas repetitivas dentro de composições complexas e ampliar as possibilidades de edição dentro do meio digital, novas formas de interação com essas plataformas foram criadas, incorporando programação dentro do processo de design. 0 desenho passou a ser planejado e vinculado à parâmetros e a operações com lógica de algoritmo - o projeto paramétrico (parametric design). Um algoritmo é um procedimento usado para retornar uma solução para uma questão — ou para realizar uma determinada tarefa - através de uma lista finita de instruções básicas e bem definidas (TEDESCHI, 2014). Vinculados aos procedimentos devidamente estruturados, essa estratégia projetual também consiste em definir relações topológicas entre as partes de elementos, sendo a definição das medidas precisas uma fase subsequente do projeto. Em geral essas dimensões podem ser selecionadas a partir de um intervalo desejável, com valores mínimos e máximos, sempre múltiplos das medidas dos componentes construtivos, resultando maior flexibilidade e variedade (MONEDERO, 2000) (Figura 1).

10 conceito de mass customization foi definido por autores como Stan Davis (1996), Tseng e Jiao (2001), Pine (1993) e Kaplan e Haenlein (2006), sendo utilizado na arquitetura por José Pinto Duarte em sua tese de doutorado, intitulada "Customizing Mass Housing: a discursive grammar for Siza's houses at Malagueira" (2001), na qual se propõe uma discussão acerca das implicações profundas da personalização em massa na arquitetura e na indústria da construção (MENDES, 2014). 
Figura 1: Exemplo de aplicação da abordagem de projeto paramétrico (MENDES, 2014).

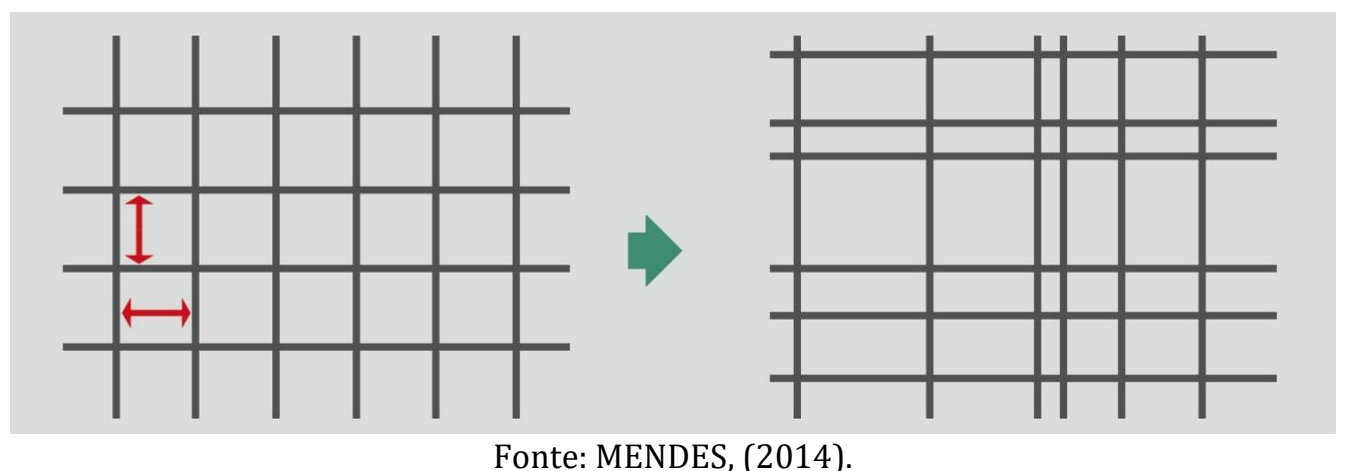

A parametrização incorpora relações associativas entre os elementos de um design, encarando essas relações como processos ao invés de resultados estáticos. Isso permite que propriedades (tanto quantitativas quanto qualitativas) sejam vinculadas à parâmetros. Tais parâmetros são interativos de maneira definida e planejada pelo designer, e permitem a rápida alteração em composições complexas, gerando resultados diversos com precisão e agilidade.

No que concerne à fabricação desses artefatos concebidos e registrados em meio digital, diversas tecnologias já são bastante populares no mercado. Esse maquinário (CNC) é capaz de interpretar os dados numéricos registrados pelos softwares em processos que concretizam perfeitamente as formas nos materiais utilizados. Os processos mais comuns são os subtrativos, aditivos e formativos. Em sua tese, Pupo (2009) adota as terminologias prototipagem e fabricação digitais, se referindo a métodos que permitem a transição do modelo digital para o físico de maneira automatizada.

\begin{abstract}
O primeiro termo, a PROTOTIPAGEM DIGITAL, inclui todas as técnicas de prototipagem rápida (sobreposição de camadas), corte a laser, fresas e corte com vinil, para a produção de maquetes em escalas reduzidas e protótipos em escala 1:1. O segundo termo, a FABRICAÇÃO DIGITAL, inclui técnicas destinadas à produção de edifícios ou partes deles (file-to-factory42, metal e tube bending). Estas, por sua vez, destinadas à produção de fôrmas ou peças finais de edifícios, com equipamentos de CNC (PUPO, 2009).
\end{abstract}

A maneiras aditiva de produzir objetos prototipados, ou seja, aqueles construídos camada por camada, são as mais populares (PUPO, 2009) (Figura 2). Todas as tecnologias de fabricação aditivas dividem o princípio de que o modelo sólido é fatiado em camadas bidimensionais. As informações referentes à cada camada são processadas pelo computador que controla o maquinário, sobrepondo camada sobre camada, gradualmente gerando o

2 File-to-factory, que numa tradução direta quer dizer "do arquivo para a fábrica", trata da produção de projetos elaborados digitalmente através da fabricação digital. Pupo (2009) caracteriza 0 processo como "quando o modelo digital 3D se comunica diretamente com as máquinas de corte programáveis". 
produto (JACOBS, 1992 apud KOLAREVIC, 2001). Utilizando esse processo de fabricação, diversas tecnologias distintas competem no mercado, utilizando vários tipos de material e processos de cura, baseados em exposição à luz, calor ou químicos. A Estereolitografia (SLA) é baseada em polímeros líquidos que se solidificam quando expostos à luz. Na Sinterização de Laser Seletivo (SLS) um raio laser derrete camada por camada de pó metálico para criar objetos sólidos. Existem ainda o 3DP, onde camadas de pó cerâmico são colados formando objetos, o LOM (Fabricação de Objetos Laminados), onde folhas de material (papel, plástico, madeira) são coladas e cortadas. No método mais difundido atualmente, a Modelagem FDM (Fused deposition modelling) conhecida como impressão 3D, cada seção transversal é produzida através do derretimento e deposição de filamento plástico que se solidifica ao resfriamento, a sobreposição dessas seções cria sólidos tridimensionais.

Figura 2: Processo aditivo de produção no laboratório do GREA3D, através do processo de impressão 3D com dois tipos diferentes de filamentos

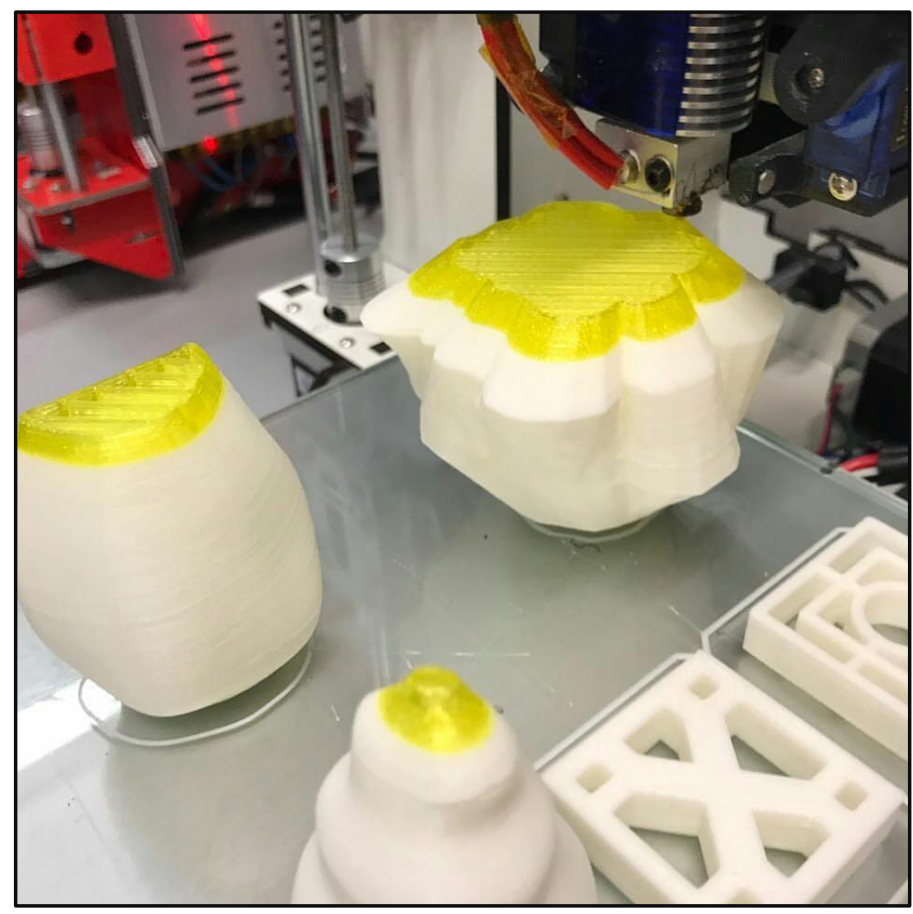

Fonte: Redes Sociais do Laboratório GREA3D, (2017).

No processo formativo de fabricação, forças mecânicas, fôrmas restritivas, calor ou vapor são aplicados em um material para molda-lo na forma desejada, através de reformação ou deformação, que pode ser restrita à um eixo ou superfície (KOLAREVIC, 2001). Com pouco uso no contexto da prototipagem, esse processo é mais aplicado na fabricação digital no dobramento e deformação mecânica precisa de peças e tubos metálicos (Metal Bending e Tube Bending).

O processo subtrativo envolve a remoção de volumes determinados do material de sólidos, utilizando por exemplo a fresagem tridimensional. $\mathrm{Na}$ fresagem CNC, um sistema de computador dedicado realiza o controle das funções e movimentos de um ferramenta, usando um conjunto de instruções 
codificadas (MCMAHON, BROWNE, 1998 apud KOLAREVIC, 2001). Essas instruções orientam precisamente o computador quanto à localização e profundidade dos cortes e riscos aplicados no material, subtraindo parte de seu volume e resultando o artefato tridimensional desejado.

Um dos procedimentos subtrativos, o corte bidimensional de materiais é a técnica de fabricação mais comum. Várias tecnologias como arco de plasma, raio laser, ou jato d'água, envolvem o movimento relativo em 2 eixos, da folha de material em relação à ponta que origina o raio/jato que realiza o corte (KOLAREVIC, 2001). No corte com arco de plasma, um arco elétrico é passado através de um gás comprimido na ponta de corte, aquecendo o gás até a forma de plasma, com uma alta temperatura $\left(14.000{ }^{\circ} \mathrm{C}\right)$, que se converte em gás novamente ao transferir seu calor para o material cortado. Nas máquinas CNC à jato d'água, um jato de alta pressão de água é misturado com partículas abrasivas e forçado através de uma saída estreita, num fluxo preciso, causando a rápida erosão do material em seu caminho, mas realizando cortes muito limpos e precisos. No presente trabalho, utilizou-se a tecnologia de corte à laser, cujo raio infravermelho de alta intensidade em combinação com um jato de gás altamente comprimido (gás ou dióxido de carbono), possibilitam derreter ou queimar o material à ser cortado (KOLAREVIC, 2001). A escolha do tipo mais indicado para cada aplicação depende do material a ser utilizados, já que cada tecnologia tem capacidades especificas de espessura e de material (PUPO, 2009). Enquanto jatos d'água podem cortar praticamente qualquer material com elevadas espessuras, as cortadoras à laser são limitadas aos materiais que conseguem absorver a energia da luz e também só cortam efetivamente pequenas espessuras.

A combinação desse novo paradigma de concepção, que idealiza rapidamente e continuamente alterações e aperfeiçoamentos na produção de artefatos, e a popularização das tecnologias de fabricação digital, massificou a prática da manufatura de produtos intermediários, seja para a documentação do processo de design, ou para constatação empírica de decisões projetuais. Essa ágil fabricação digital de protótipos, de produtos-teste intermediários, tem sido denominada de prototipagem rápida. A medida que o conjunto de tecnologias conhecidas como prototipagem rápida emerge e é absorvido na prática, ele tem sido reconhecido como um avanço de potencial significado para o design (SASS, 2006). Pois através desse método, modelos em escalas menores são feitos rapidamente, usando máquinas de prototipagem rápida que transformam os dados virtuais em modelos físicos com elevada precisão (IWAMOTO, 2013, p. 5). A distinção entre os objetivos do produto fabricado determina a terminologia processo digital aplicado, segundo Pupo (2011):

Os métodos de prototipagem (prototyping) são destinados à produção de protótipos ou modelos de avaliação e utilizados durante a concepção do projeto e auxiliam na avaliação das alternativas geradas. Quando esses produtos (ou elementos construtivos) são utilizados diretamente na construção, referem-se ao sistema de fabricação (fabrication) ou manufatura (manufacturing) (PUPO et al, 2011). 
Diante desse novo horizonte, aberto pela popularização crescente das técnicas de fabricação digital, diversas universidades internacionais e nacionais têm apresentado um crescente número de experimentos com o objetivo de discutir as transformações ocorridas no processo projetual a partir da introdução das tecnologias digitais, tais como os sistemas generativos de projeto, como, por exemplo, a modelagem paramétrica e as técnicas de PR e FD (Figura 3).

Figura 3: Exemplos de experiências projetuais desenvolvidas em universidades internacionais e nacionais: (1) Instant House - projeto desenvolvido no Massachusetts Institute of Technology (MIT), coordenado pelo professor Dr. Larry Sass (SASS, 2008); (2) Casa Generativa (Casa G), projeto desenvolvido na Universidade Federal do Rio Grande do

Sul - UFRGS, coordenado pelos professores Dr. Benamy Turckienicz e Dr. Rodrigo Garcia Alvarado (CASA G., 2010); (3) Estrutura desenvolvida na Universidade Estadual de Campinas (UNICAMP), coordenada pelas professoras Dra. Gabriela Celani e Dra. Regiane Pupo (PUPO et al, 2011).

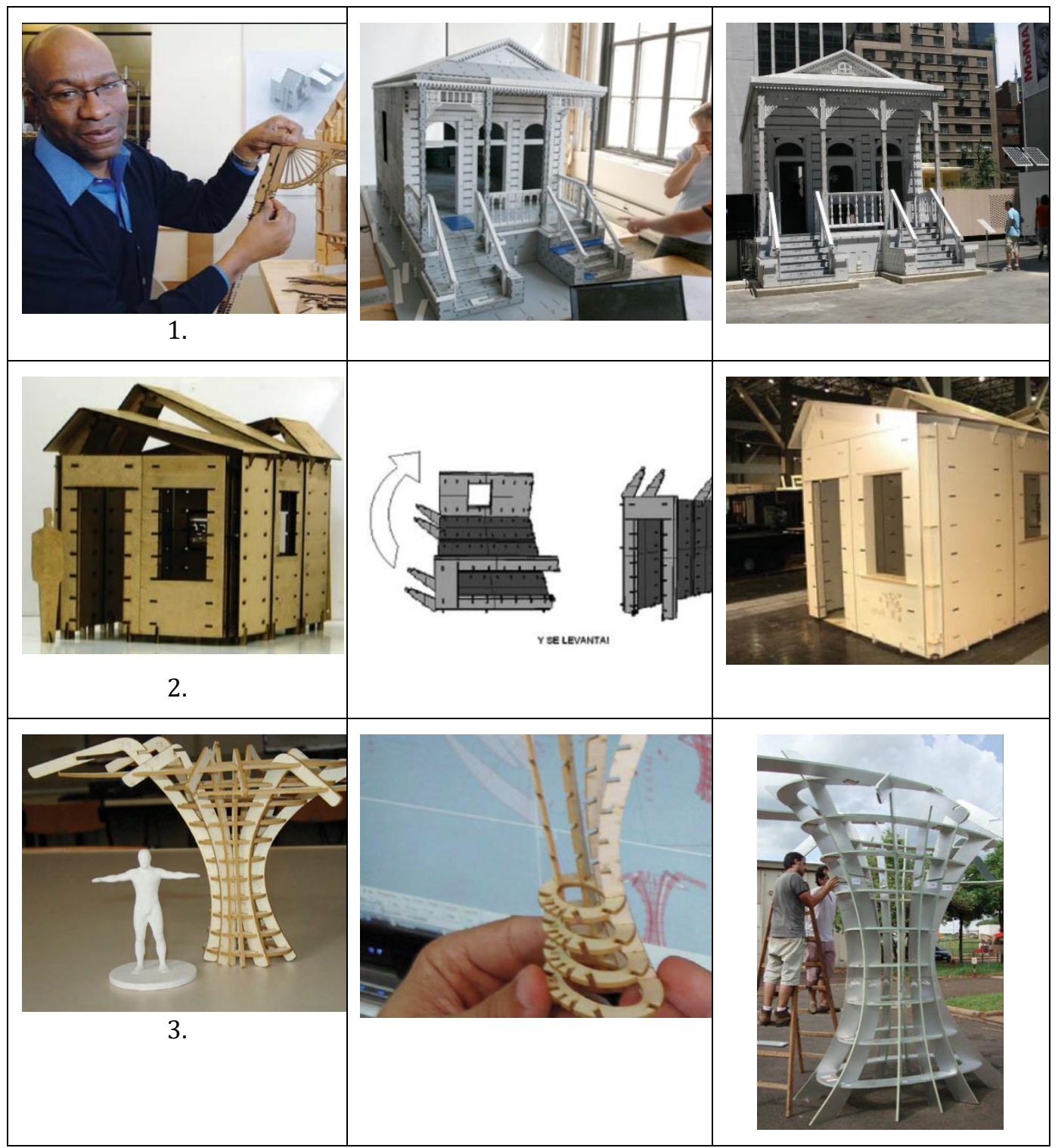

Fonte: (1) SASS, (2008); (2) CASA G., (2010); (3) PUPO et al, (2011). 
Dentro desse contexto, no ano de 2017 houve a inauguração de um laboratório dentro do Departamento de Expressão Gráfica da Universidade Federal de Pernambuco - o Grupo de Experimentação em Artefatos 3D, ou GREA3D. O laboratório GREA3D, surgiu da necessidade didática de pesquisas desenvolvidas em disciplinas e projetos de iniciação científica envolvendo temas como prototipagem e fabricação digital, sistemas generativos de projeto, robótica, modelagem paramétrica, entre outras disciplinas onde a prática seria enriquecida com um laboratório dotado de equipamentos de automação no processo de projeto. Essa iniciativa foi viabilizada com recursos de instituições de fomento à pesquisa, dentre outras parcerias e dispõe de diversas Impressoras 3D e uma Cortadora à laser, que são operadas por monitores, alunos do curso de Expressão Gráfica e Arquitetura e Urbanismo (Figura 4).

Figura 4: Máquina de corte CNC à laser em funcionamento.

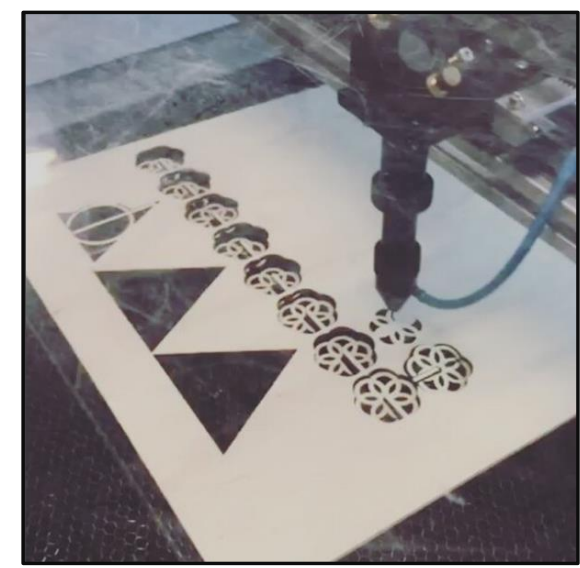

Fonte: Redes Sociais do Laboratório GREA3D, (2017).

0 presente trabalho tem como objetivo descrever o desenvolvimento de um projeto de mobiliário - um painel para exposição de objetos e organizador de ferramentas - concebido por um aluno do curso de Arquitetura e Urbanismo durante o período de Estágio Curricular Institucional 1, da UFPE. 0 resultado do experimento, seria exposto na inauguração oficial do laboratório e, posteriormente, seria usado no dia a dia. Além disso, o painel deveria ser fabricado dentro do laboratório e a partir do uso dos seus equipamentos de PR e FD.

Frente a todos os novos paradigmas aqui expostos, e realizando um trabalho dentro de um laboratório de prototipagem, as escolhas projetuais do aluno refletiram a vontade de incorporar esses aspectos em um experimento interessante, no sentido pedagógico, pelo empirismo envolvido, e no sentido simbólico, de produzir um painel condizente com os desafios e práticas da atualidade. Assim, o partido projetual foi definido: unir a potencialidade das tecnologias de prototipagem rápida, aberta pela disponibilidade dos equipamentos presentes no laboratório, com a relevância do desenho paramétrico, na agilidade dos ajustes e aperfeiçoamentos do design. 
A seguir será apresentado o processo de concepção e fabricação do painel paramétrico para o laboratório GREA3D — produto da combinação da abordagem de parametrização e de tecnologias de fabricação digital - desde a sua concepção ao processo de corte e montagem.

\section{METODOLOGIA DE DESENVOLVIMENTO, PROTOTIPAGEM E}

\section{FABRICAÇÃO}

0 painel deveria ter dimensões 2,10 $\mathrm{m} \mathrm{x} \mathrm{1,10} \mathrm{m,} \mathrm{ser} \mathrm{fixado} \mathrm{na} \mathrm{parede}$ e funcionar como um painel de ferramentas para o dia a dia do laboratório. Dentre as exigências estabelecidas, precisaria garantir o afastamento da parede por conta da tubulação aparente do sistema de ar-condicionado tipo Split instalado no ambiente (Figura 5).

Figura 5: A parede com ar-condicionado onde foi colocado o painel, ainda em processo de pintura.

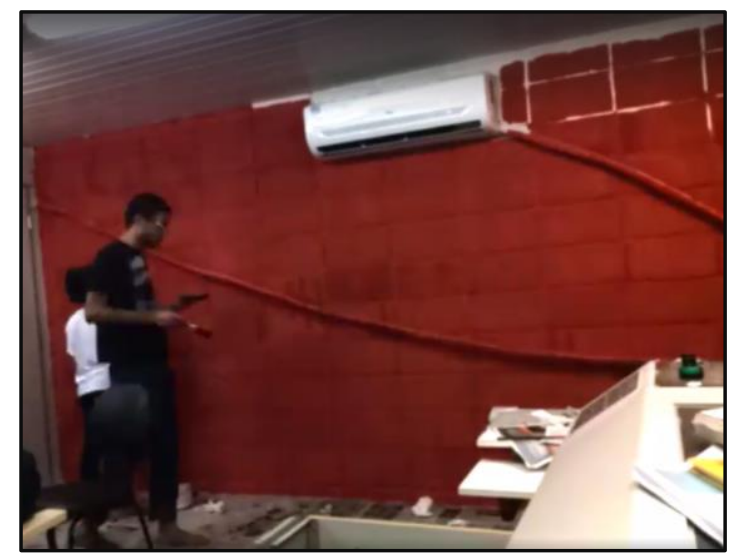

Fonte: Redes Sociais do Laboratório GREA3D, (2017).

A fonte de inspiração para o design foi a identidade visual do laboratório, escolhida mediante concurso no ano anterior (2016). 0 logotipo bidimensional desenvolvido sugere uma figura tridimensional com a adição de cores contrastantes (Figura 6). Dessa forma, a concepção projetual objetivou materializar o logotipo enquanto figura tridimensional, utilizando posteriormente suas formas para as finalidades de exposição e suporte de ferramentas.

Figura 6: 0 Logotipo do laboratório, à esquerda em versão de apenas linhas, e à direita a versão colorida

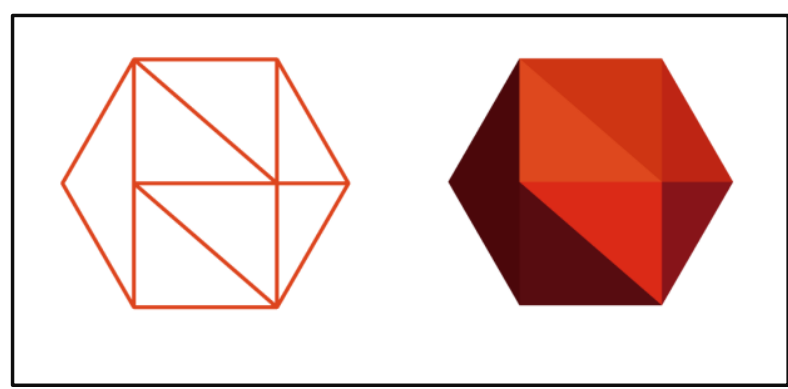

Fonte: Redes Sociais do Laboratório GREA3D, (2017). 


\subsection{Código e modelagem}

A codificação e modelagem do artefato foi realizada através do software de modelagem 3D Rhinoceros 5 e do plugin Grasshopper. 0 Grasshopper é um editor gráfico de algoritmos, completamente integrado com as ferramentas de modelagem do Rhinoceros. Sem a necessidade de conhecimento profundo das linguagens de programação envolvidas, esse plugin permite os projetistas construírem geradores de forma, do mais simples ao mais complexo (GRASSHOPPER, 2017). Com o uso dessas ferramentas foi possível a geração da forma tridimensional do painel, mediante à parâmetros definidos dentro do projeto para ajusta-lo perfeitamente ao seu ponto de implantação.

O desenho conceitual elaborado estabeleceu como ponto de partida um artefato tridimensional cuja projeção de vista frontal remetesse ao logotipo original, com isso ficou claro que ele precisaria conter os elementos triangulares já presentes no logotipo. Para dar conta da longa área útil, esses elementos foram separados em 3 grupos fundamentais afastados entre si. Nos espaços restantes da superfície, foram dispostas prateleiras curvilíneas, com variações parametrizadas de profundidade. Essas prateleiras, por serem elementos horizontais e planas, não atrapalhariam as visualização frontal intuída do logotipo e dariam unidade à composição. Pela dimensão alongada disponível para o painel, o logo precisou ser centralizado posteriormente, por sugestão dos próprios professores, algo que foi realizado rapidamente, mediante ajuste de parâmetros.

Pela fabricação definida se tratar de um processo de corte bidimensional, todos os objetos que compunham o artefato exigiram serem decompostos em curvas planares para poderem ser produzidos. Por isso a preocupação primaria na parametrização era de conseguir criar as superfícies que geravam os volumes do painel. Os demais detalhes, como os encaixes entre essas peças, seriam implementados posteriormente, tendo como referência essas superfícies já definidas.

O primeiro parâmetro de partida definido foi a própria área do painel, uma superfície plana, ortogonal, e foi referência para diversos procedimentos dentro do design. Essa área foi dividida respeitando as proporções do logotipo e mantendo a identidade do símbolo. As superfícies resultantes da divisão foram então subdivididas nos triângulos do logotipo e rotacionadas para fora do plano de uma maneira que a figura projetada sobre a superfície da parede na vista frontal remetesse exatamente ao símbolo original (Figura 7). Essas superfícies foram então usadas como referência para gerar os seu "fechamentos" - outras superfícies, perpendiculares à área útil, que conectariam seus vértices e arestas deslocados ao plano original, conferindo volume unitário para cada grupo das peças triangulares. 
Figura 7: À esquerda as arestas do logotipo que originaram os volumes presentes no painel, à direita

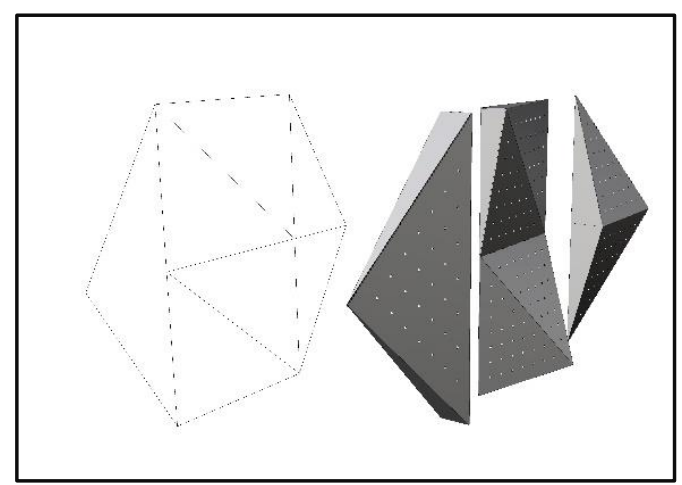

Fonte: Acervo do autor, (2017).

As prateleiras foram geradas a partir de 4 parâmetros básicos: uma profundidade mínima, uma profundidade máxima, a distância entre elas (altura máxima dos objetos colocados) e uma entrada de curvas. Essas curvas de entrada tem uma função modeladora no conjunto de prateleiras, gerando variação na profundidade delas conforme a distância para essas curvas desenhadas (Figura 8). Após isso, o desenho final das prateleiras era então ajustado para concordar com as arestas dos volumes do logotipo, arrematando nos pontos de intersecção entre o plano de cada prateleira e os volumes do logotipo.

Figura 8: Em amarelo curvas usadas para o desenho das prateleiras no painel

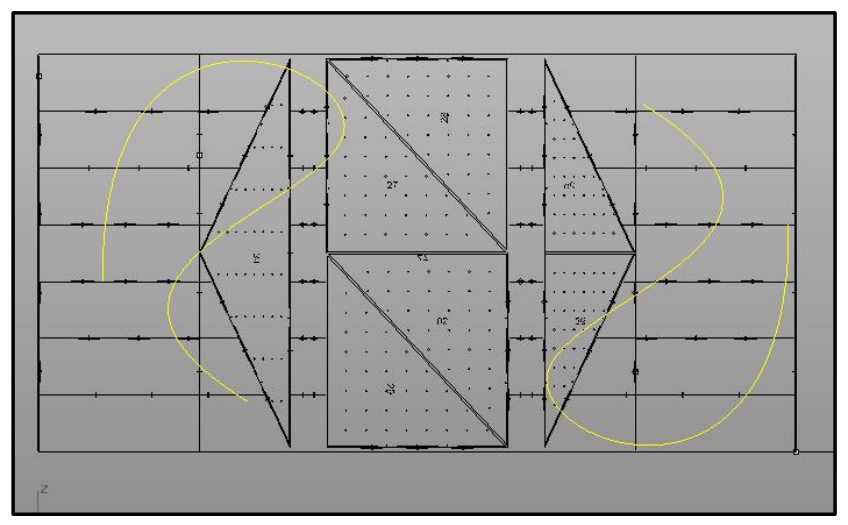

Fonte: Acervo do autor, (2017).

O logotipo foi pensado para além de elemento escultórico ter a finalidade de suporte de ferramentas. Para isso outra função realiza a perfuração das placas, em um grid de orifícios circulares semelhantes aos encontrados nos painéis metálicos Eucatex, já usados frequentemente com a finalidade de guardar ferramentas.

Apenas um tipo de encaixe foi utilizado em todo artefato, e a implementação dele foi uma das mais interessantes dentro desse experimento, pois tem grande potencial para ser repetida (e aperfeiçoada) em designs posteriores. Dentro desse projeto os encaixes foram implantados a partir de uma função que recebe as peças a serem encaixadas, tamanho e número de encaixes entre elas, e desenha os detalhes desses encaixes de forma 
automática. 0 encaixe consiste no prolongamento retangular de trechos das placas, que passam a penetrar as outras através de orifícios retangulares também desenhados. Em cada lado desses prolongamentos e orifícios são dispostos outros dois buracos, feitos para a passagem de abraçadeiras de nylon, que fixam de forma permanente as peças encaixadas. Esta foi uma solução muito prática e baixo custo para a execução do projeto, por gerar um processo de montagem completamente manual, sem necessidade de ferramentas.

A agilidade da modelagem paramétrica permitiu a concepção de variados designs preliminares (Figura 9), cada um dos quais foram submetidos ao julgamento do usuários do laboratório. Isso permitiu que fossem integradas as qualidades mais relevantes ao produto final.

Figura 9: Diversos designs preliminares elaborados e julgados pelos usuários do laboratório

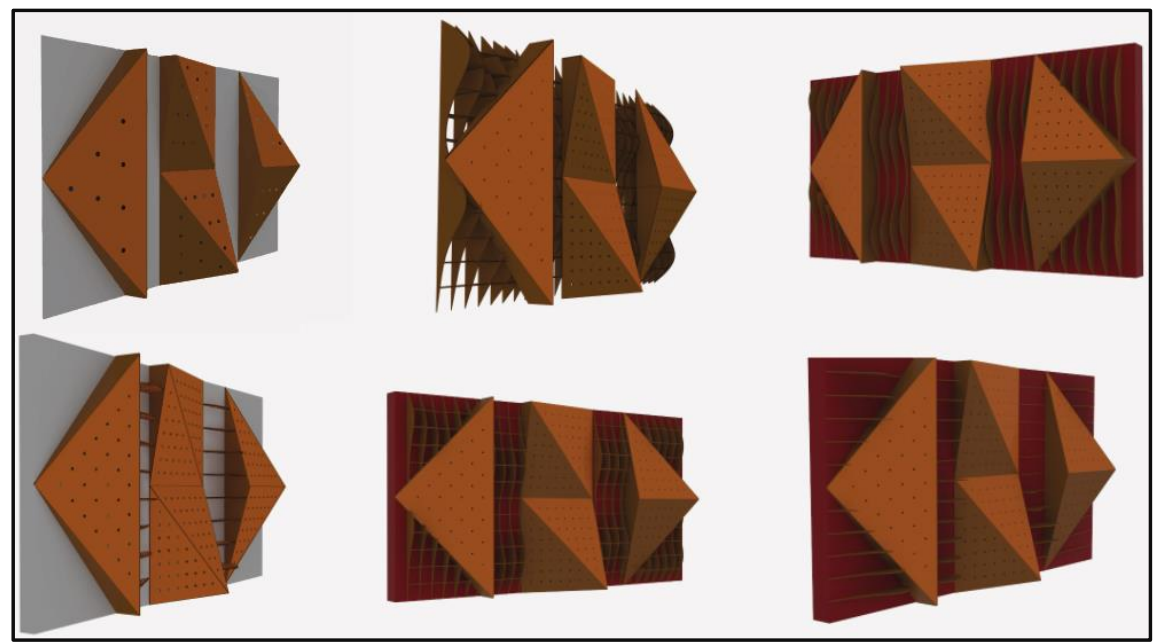

Fonte: Acervo do autor, (2017).

Após a aprovação do design final, foi preciso transferir a geometria implementada dentro do Grasshopper (Figuras 10 e 11) para o Rhinoceros, para então fabricar os primeiros protótipos, com finalidade de teste do material e da volumetria do painel. Assim, por meio da prototipagem rápida, seria possível constatar a eficiência do sistema de encaixe, além de permitir explorar a possível ergonomia do produto final.

Figura 10: A estrutura do algoritmo implementado no Grasshopper

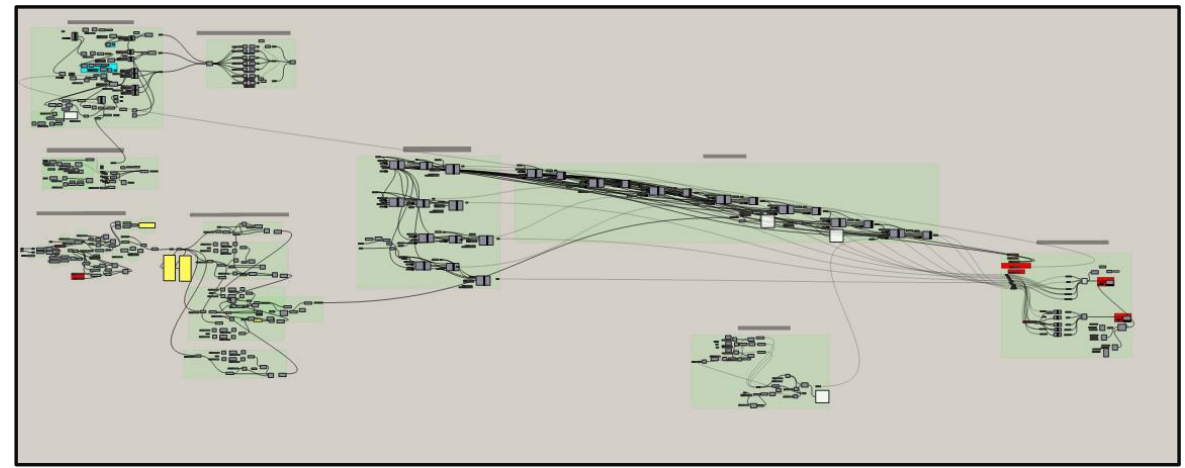

Fonte: Acervo do autor, (2017). 
Figura 11: Um esquema conceitual do processo até o design final

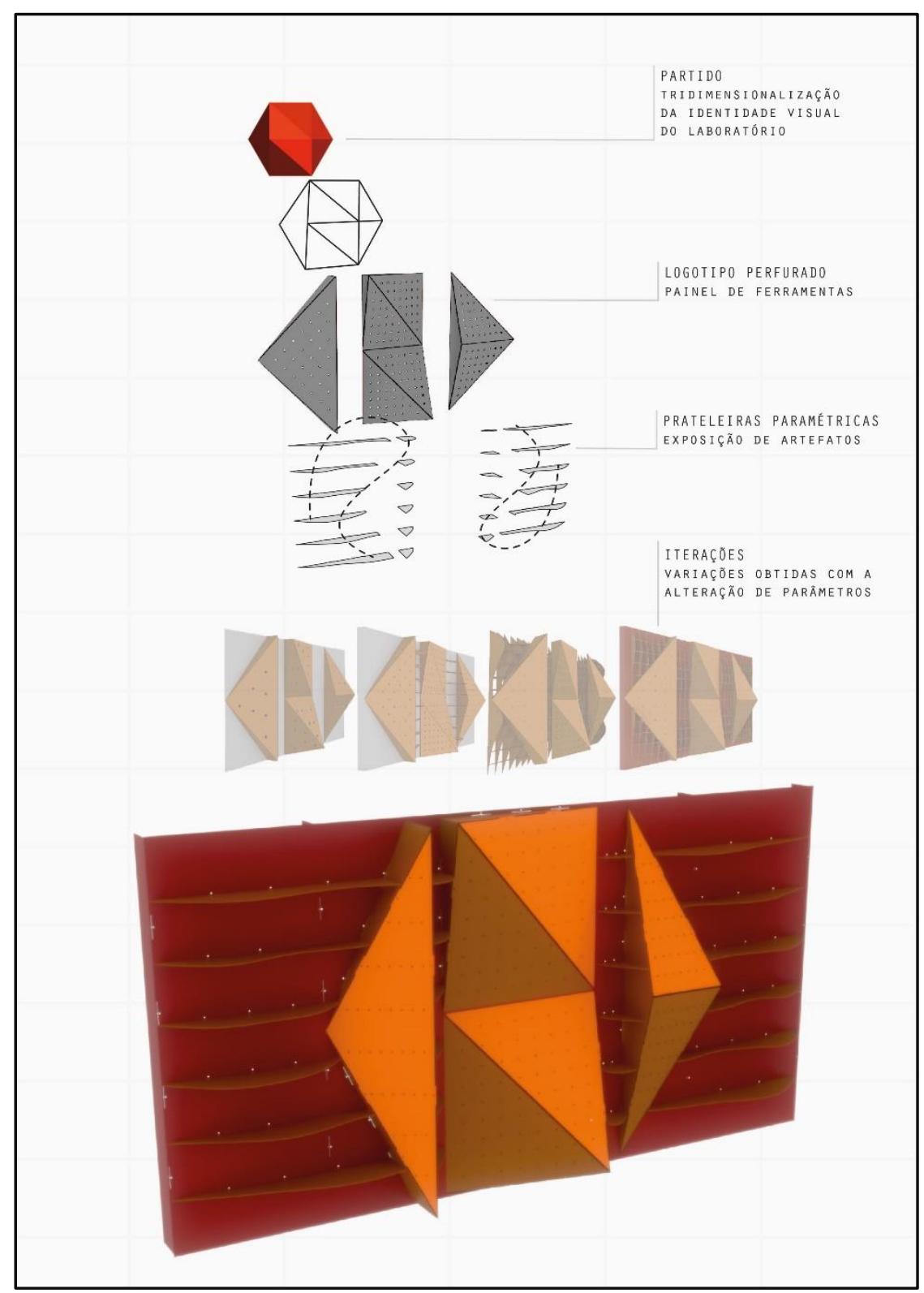

Fonte: Acervo do autor, (2017).

\subsection{Prototipagem}

0 material utilizado para prototipagem do painel foi o mesmo utilizado no produto final. 0 processo de prototipagem rápida do painel utilizou folhas de MDF, com 1 e 3 milímetros de espessura, cortadas com cortadora CNC à laser. A máquina do laboratório tem a capacidade máxima de corte de uma chapa de $0,90 \mathrm{~m} \times 1,20 \mathrm{~m}$, tendo sido testado corte de MDF de até $5 \mathrm{~mm}$ de espessura. Foi necessário realizar alguns testes para verificar as melhores potências e velocidade de corte para o MDF de $3 \mathrm{~mm}$, antes de seguir para o primeiro protótipo. 
Os parâmetros mais ajustados nessa fase - os que justificaram a implementação paramétrica do projeto - foram o relativo a espessura do material, a folga do laser e o comprimento dos encaixes. Relativizar a modelagem em relação à espessura do material permitia o ajuste imediato do design para qualquer espessura de material, permitindo que fosse utilizado qualquer um dos materiais disponíveis no estoque do laboratório para teste. Como o laser da máquina realiza os cortes queimando o material, esses cortes influenciam diretamente área final das superfícies subtraídas das chapas. Foi ajustando o parâmetro de folga do laser que se verificou empiricamente a espessura em milímetros do corte realizado pela máquina, e foi possível ajustar as dimensões dos cortes para levar em consideração esse aspecto. Por fim, como os testes dos protótipos seriam feitos em escalas menores, para não desperdiçar material, o comprimento dos encaixes também foram regulados para cada caso.

O primeiro protótipo produzido foi uma versão em escala reduzida (1:10) de parte do painel, em chapa de MDF de $1 \mathrm{~mm}$, contendo uma das partes do logo e sua superfície de suporte. Esse protótipo se mostrou insuficiente para ser montada com êxito, pela escala exageradamente reduzida. Mas serviu para a compreensão da melhor folga do laser para essa espessura.

O segundo protótipo produzido foi uma versão em escala ligeiramente maior (1:7) das mesmas partes do painel, dessa vez utilizando a espessura 3 $\mathrm{mm}$ (presente no produto final), contendo as mesmas partes do painel. Nesse protótipo se verificou mais um problema no design: as peças falhavam em levar em consideração a forma como espessura das placas cortadas influenciavam no encaixe entre elas. Nesse protótipo os elementos cortados se mostravam ligeiramente maiores que o espaço disponível para sua junção, porque o design ainda os contabilizava como elementos planares, sem espessura.

Após implementação do parâmetro da espessura do material, foi realizado o corte em escala real das mesmas partes do painel. Ainda assim foi necessário o ajuste desse parâmetro no corte final. 0 primeiro protótipo cortado em escala real ainda apresentou problemas de encaixe (Figura 12), embora tenha conseguido ser propriamente montado.

Figura 12: Primeiro protótipo em escala real, com problemas de encaixe

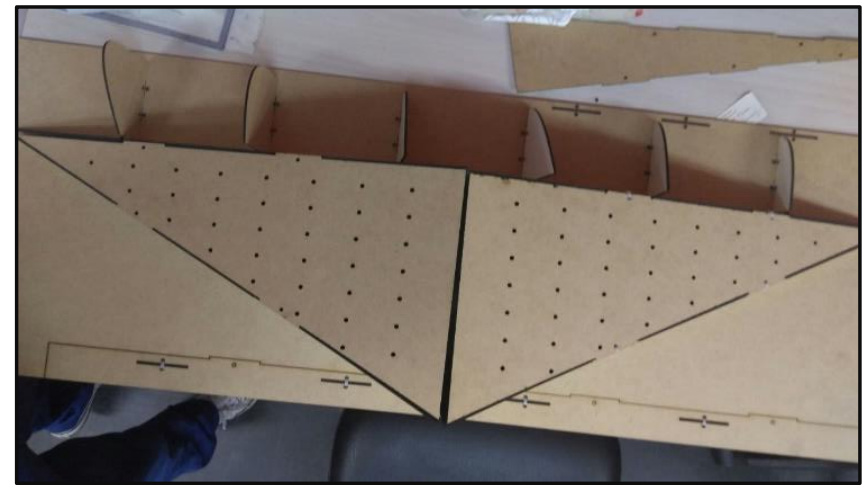

Fonte: Acervo do autor, (2017). 
A execução desses testes preliminares foram dando, aos poucos, confiança e viabilidade ao projeto. Após a produção desses protótipos, houve discernimento em relação a problemas não previstos, mas que puderam ser solucionados antes da etapa seguinte: a fabricação.

\subsection{Fabricação}

Nesta etapa, foram realizadas as atividades finais de produção do artefato: o corte e montagem dos elementos.

No primeiro momento foi necessário o posicionamento das peças a serem cortadas foi otimizado para minimizar os gastos de material, um procedimento chamado de nesting (Figura 13). Um plugin chamado RhinoNest foi utilizado para realizar essa tarefa de forma automatizada, levando em consideração a dimensão das placas compradas para a fabricação $(0,90 \mathrm{~m}$ x $1,20 \mathrm{~m}$ ). Só então foi realizada a conversão dos arquivos produzidos pelo software Rhinoceros para o formato legível pelo software usado no computador que controlava a máquina CNC (formato STL).

Figura 13: Nesting de peças numa das placas.

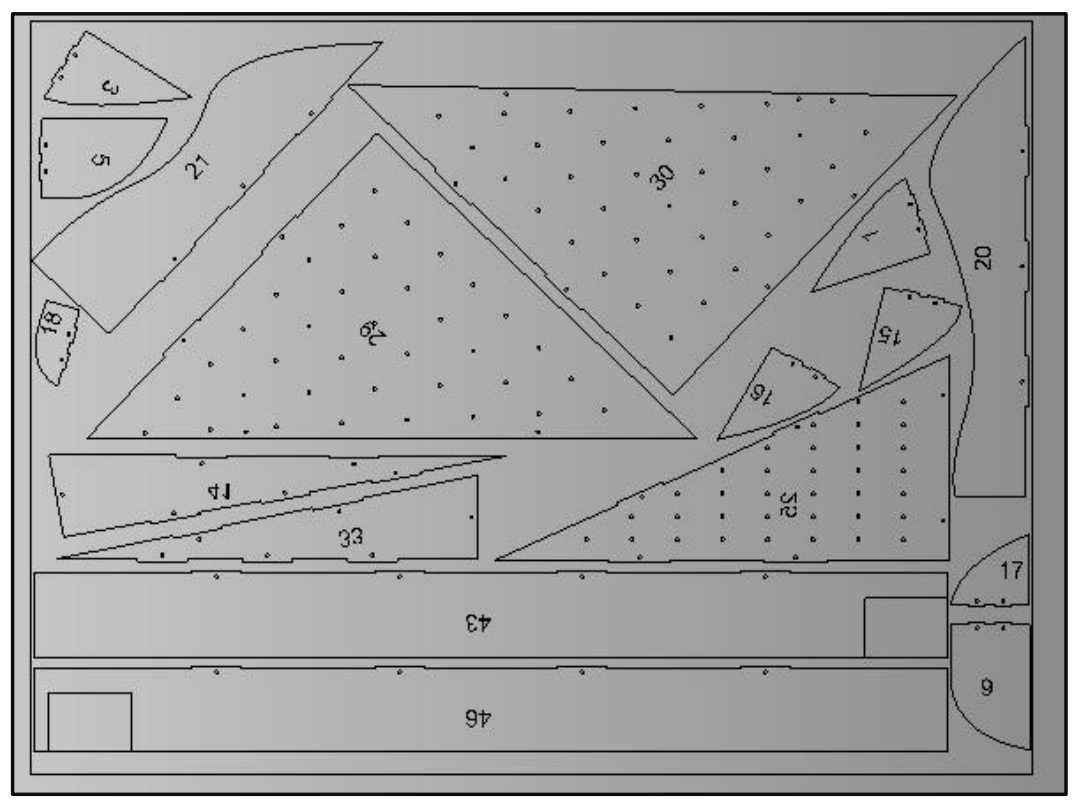

Fonte: Acervo do autor, (2017).

No entanto algumas questões sofreram alterações não previstas, que só foram confrontadas no momento de fabricação. Por questões de economia e praticidade, uma placa grande com a dimensão exata do painel $(1,10 \mathrm{~m} x$ $2,10 \mathrm{~m}$ ) e já com acabamento vermelho de fábrica, foi comprada. Essa placa era ainda mais grossa que as demais, com $5 \mathrm{~mm}$ de espessura, para dar mais estabilidade ao painel. Por ser mais grossa, demorou muito mais para ser cortada, e por ser mais longa precisou ser cortada em 3 partes para poder receber os cortes dos encaixes. Por trás dessa placa foram então fixados perfis metálicos que uniram essas placas de fundo com firmeza e que, apoiados em mãos francesas metálicas, sustentaram o painel na parede. Além disso, as placas MDF compradas tinham tratamentos diferentes em cada uma de suas 
faces. Uma das faces era MDF cru, e a outra possuía um acabamento plástico branco. Como as peças cortadas foram pintadas com spray de tinta laranja, esses elementos tiveram adesão diferenciada das tintas, tendo colorações ligeiramente diferentes em cada face. 0 design não levou em consideração uma orientação em relação as faces do material, o que gerou algumas discrepâncias cromáticas e direcionais no produto final. Apesar desses fatos não previstos, o painel foi montado (Figura 14) e apresentado de forma satisfatória.

Figura 14: 0 painel em processo de montagem.

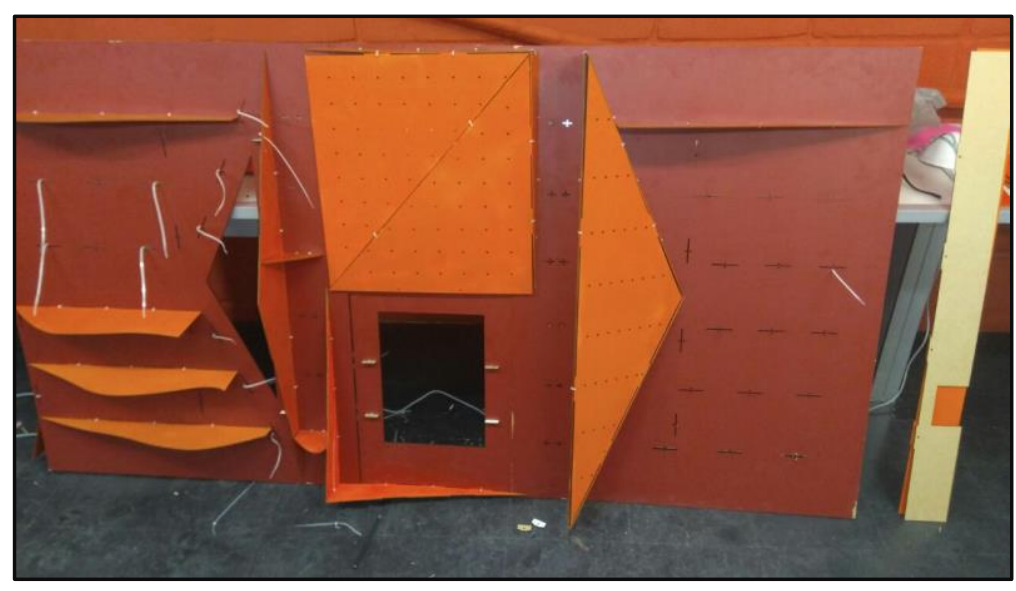

Fonte: Acervo do autor, (2017).

\subsection{Produto final}

No produto final, foram dispostos artefatos já produzidos no laboratório, por corte à laser e impressão 3D (Figuras 15, 16 e 17). As prateleiras do painel acabaram servindo para esse propósito de exposição, mas tem a capacidade bem limitada de carga: por conta do contraste entre a profundidade muito superior à espessura das prateleiras, essas ficaram ligeiramente instáveis e fletem quando expostas a cargas consideráveis. Apesar disso, elas conseguem suportar as obras, geralmente leves, produzidas no laboratório, e cumprem com a finalidade de exposição.

Figuras 15 e 16: 0 painel terminado.
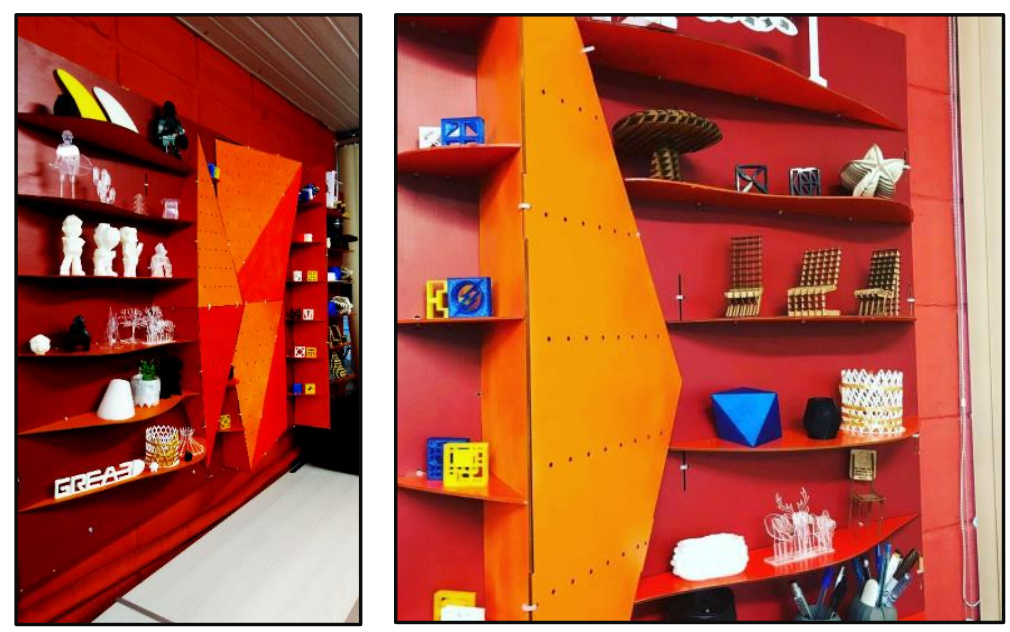

Fonte: Acervo do autor (2017). 
Figuras 17: Vista frontal do painel concluído.

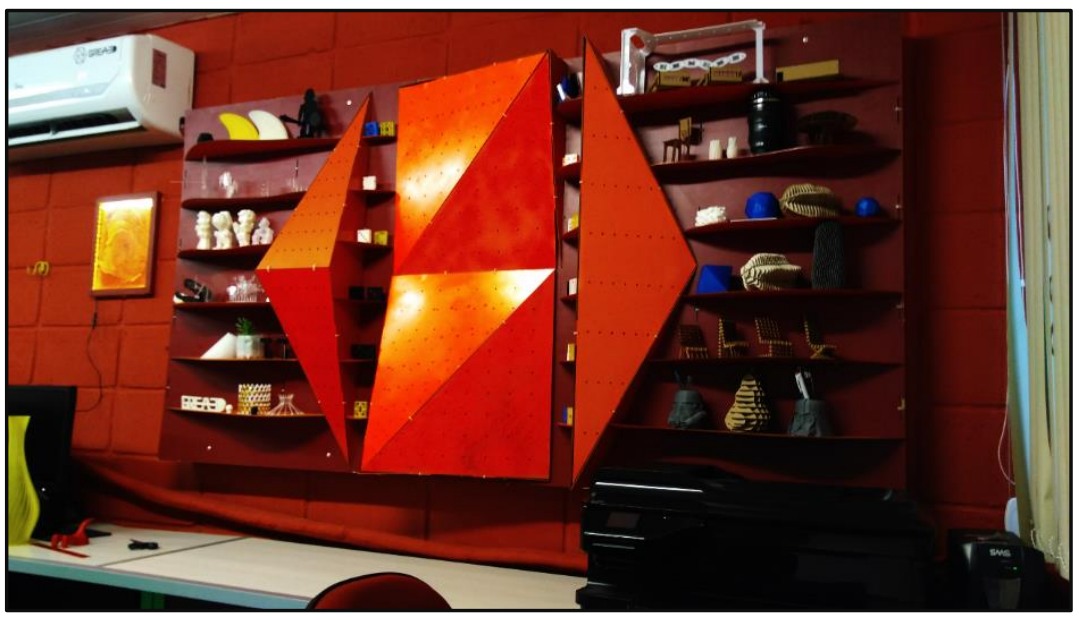

Fonte: Acervo do autor (2017).

\section{CONCLUSÕES}

O desenvolvimento deste exercício proporcionou a discussão de aspectos do projeto que justificam o uso das novas tecnologias aplicadas, explanando a influência da parametrização e prototipagem na fabricação do painel executada.

Considerando a experiência do autor do projeto, esse trabalho constituiu uma oportunidade de explorar o uso combinado da modelagem paramétrica e da aplicação da prototipagem rápida no processo projetual. A agilidade inerente à modelagem paramétrica e a concepção de um processo ao invés de um produto, permitiu a concepção de vários artefatos preliminares, que puderam ter suas qualidades julgadas, antes da fabricação. As variadas características do design foram incorporadas de forma associativa, o que gerou uma experiência muito mais integral de concepção. Nela cada escolha de projeto era obrigatoriamente rebatida nas demais relações existentes entre os elementos da composição. Além disso, essas relações precisaram englobar a viabilidade física do artefato, demandando uma preocupação constante com os aspectos da fabricação, justamente pelo controle e envolvimento direto do projetista nesse processo. Essa é uma das grandes possibilidades aberta pelas tecnologias de fabricação digital, claramente envolvida nessa aproximação, como cita Kolarevic (2010):

\footnotetext{
"Conhecendo as capacidades de produção e disponibilidade de um equipamento de fabricação controlado digitalmente permite que projetistas projetem especificamente para as capacidades dessas máquinas. A consequência é que os projetistas estão se tornando muito mais diretamente envolvidos no processo de fabricação, uma vez que criam a informação que é interpretada pelo fabricante diretamente dentro do dado de controle, que guia o equipamento de fabricação digital" (KOLAREVIC, 2010, p.71, apud BARBOSA NETO, 2013).
}

Embora tenha sido mais utilizada nas etapas finais da concepção do artefato, a prototipagem rápida, através da produção de modelos 
intermediários, foi fundamental para a compreensão dos aspectos materiais, ajustes e materialização do projeto. A combinação dessa constatação empírica com a possibilidade de correção rápida de erros num processo digital, mediante alteração de parâmetros definidos, corrobora com a afirmação de que "esse processo computadorizado simplifica a produção, efetivamente misturando processos de concepção e de detalhamento tipicamente compartimentalizados, e com frequência eliminando degraus intermediários entre o design e o produto final" (IWAMOTO, 2013). Essa mistura de concepção e fabricação na visão de Sass permite uma "manipulação conceitual simultânea dos aspectos de configuração espacial, comportamento físico e material e fabricação do projeto" que "parece apresentar um potencial verdadeiramente único para um projeto integrado" (SASS, 2006). Potencial refletido justamente no benefício pedagógico do envolvimento mais claro do projetista com o processo de fabricação, que restabelece materialidade ao projeto concebido no meio virtual.

\section{REFERÊNCIAS BIBLIOGRÁFICAS}

BARBOSA NETO, Wilson. Do projeto à fabricação: um estudo de aplicação da fabricação digital no processo de produção arquitetônica. 2013.133 p. Dissertação (mestrado) - Universidade Estadual de Campinas, Faculdade de Engenharia Civil, Arquitetura e Urbanismo, Campinas, SP. Disponível em: <http://www.bibliotecadigital.unicamp.br/document/?code $=000926019 \& 0$ pt=1>. Acesso em: 3 abr. 2017.

CASA G - Casa Generativa para Rio Grande do Sul [Internet]. Porto Alegre PVE Capes Propar UFRGS: Benamy Turckienicz; Rodrigo Garcia Alvarado. 2010 [acesso em 04 Jun. 2010]. Disponível em: http://casagenerativa.blogspot.com/.

CELANI, G.; PUPO, R. Prototipagem Rápida e Fabricação Digital para arquitetura e construção: Definições e estado da arte no Brasil. In: Caderno de Pós-graduação em Arquitetura e Urbanismo. São Paulo: 2008.

GRASSHOPPER. About Grasshopper. Grasshopper - algorithmic modeling for Rhino, 2017. Disponivel em: <http://www.grasshopper3d.com>. Acesso em: 15 jul. 2017.

IWAMOTO, Lisa. Digital fabrications: architectural and material techniques. Princeton Architectural Press, 2013.

KOLAREVIC, Branko. Digital fabrication: manufacturing architecture in the information age. ACADIA, 2001.

MENDES, L. T. Personalização de habitação de interesse social no Brasil: o caso da implantação urbana em conjuntos habitacionais. Tese de Doutorado. Universidade Estadual de Campinas, 2014. 
MONEDERO, J. Parametric design: a review and some experiences. Automation in Construction, Volume 9, Issue 4, July 2000, Pages 369-377.

PUPO, R., MARTINO, J. MENDES, L. Da parametrização à fabricação digital. In: XV Congresso da Sociedade Ibero-Americana de Gráfica Digital (SIGRADI), 2011, Santa Fé. SIGRADI 2011 - Cultura Aumentada. Santa Fé, 2011.

PUPO, Regiane Trevisan. Inserção da prototipagem e fabricação digitais no processo de projeto: um novo desafio para o ensino de arquitetura. 2009. 240 p. Tese (doutorado) - Universidade Estadual de Campinas, Faculdade de Engenharia Civil, Arquitetura e Urbanismo, Campinas, SP. Disponível em: $<$ http://libdigi.unicamp.br/document/?code $=000442574>$. Acesso em: 30 mar. 2017.

SASS, L.; OXMAN, R. Materializing design: the implications of rapid prototyping in digital design. Design Studies, v. 27, n. 3, p. 325-355, 2006.

SASS, L. A digitally fabricated house for New Orleans. Massachusetts Institute of Technology, USA, 2008.

TEDESCHI, A. Algorithms-Aided Design: Parametric Strategies using Grasshopper. 1a․ ed. Montecalvario: Le Penseur, 2014.

\section{AGRADECIMENTOS}

Meus agradecimentos são ao Grupo de Experimentação em Artefatos 3D, pela oportunidade, confiança e apoio financeiro dados ao projeto, e à FACEPE, entidade que financiou o laboratório dentro da Universidade Federal de Pernambuco. 